\title{
Differential Regulation of Genes Encoding Ethylene Biosynthesis Enzymes and Ethylene Response Sensor Ortholog during Ripening and in Response to Wounding in Avocados
}

\author{
Willis Omondi Owino, Ryohei Nakano, Yasutaka Kubo, and Akitsugu Inaba ${ }^{1}$ \\ Laboratory of Postharvest Agriculture, Faculty of Agriculture, Okayama University, Tsushima, Okayama \\ 700-8530, Japan
}

\begin{abstract}
ADDiTIONAL INDEX WORDS. 1-aminocyclopropane-1-carboxylate (ACC), ethylene biosynthesis, ethylene response sensor 1 (ERS1), fruit ripening, gene expression, wounding

Abstract. We investigated the differential regulation of two 1-aminocyclopropane-1-carboxylate synthase (ACS) genes, one 1-aminocyclopropane-1-carboxylate oxidase (ACO) gene and one ethylene response sensor (ERS1) ortholog during ripening and in response to wounding in avocados (Persea americana Mill. 'Bacon'). The 1-aminocyclopropane-1carboxylate (ACC) content, ACS activity and detectable expression of $P A-A C S 1 \mathrm{mRNA}$ increased and reached a maximum prior to the climacteric peak, whereas ACO activity and the $P A-A C O$ mRNA levels increased markedly only at the upsurge of ripening ethylene. A basal level of $P A-E R S 1$ transcript was detected as from harvest, however, $P A-E R S 1$ transcript was hyper-induced at the climacteric peak of ethylene production. 1-Methylcyclopropene (1-MCP) application at thepreclimacteric and the onset of climacteric stages inhibited the ACS and ACO activities, the transcription of $P A-A C S 1$ and suppressed $P A-A C O$ and $P A-E R S 1 \mathrm{mRNAs}$ to trace levels. Discontinuation of 1-MCP treatment led to super-induction of $P A-A C S 1, P A-A C O$, and $P A-E R S 1$ transcripts. Wound induced ethylene biosynthesis and woundinduced $P A-A C S 2 \mathrm{mRNA}$ accumulation were enhanced by $1-\mathrm{MCP}$, whereas wound-induced $P A-A C O$ mRNA accumulation was unaffected by $1-M C P$. These results indicate positive feedback regulation of the $P A-A C S 1$ gene and negative feedback regulation of the $P A-A C S 2$ gene by ethylene, while $P A-A C O$ exhibits positive feedback regulation by ethylene and is also induced by wounding. The hyper-induction of $P A-E R S 1 \mathrm{mRNA}$ at relatively high concentrations of ethylene may be a mechanism of avocados to regulate the ethylene responsiveness of the tissues by dissipation of the gas.
\end{abstract}

The phytohormone ethylene is a gaseous alkene, which acts as a potentiator or enhancer in a diverse range of physiological processes such as fruit ripening, germination, flower and leaf senescence, leaf abscission, cell-fate determination in the root epidermis, root nodulation, sex determination, programmed cell death, and responsiveness to stress and pathogen attack (Stepanova and Ecker, 2000).

It is well documented that the pathway of ethylene biosynthesis proceeds via methionine through $\mathrm{S}$-adenosyl methionine (SAM) and 1-aminocyclopropane-1-carboxylate (ACC) to ethylene (Yang and Hoffman, 1984). ACC synthase (ACS) catalyzes the cyclization of SAM to ACC, and is encoded by divergent multigene families, each member of the gene family being differentially expressed in response to various factors (Yang and Hoffman, 1984; Zarembinski and Theologis, 1994). ACC oxidase (ACO) catalyzes the oxidative conversion of ACC to ethylene (Yang and Hoffman, 1984). The gene expression of this enzyme is constitutive in most vegetative tissues but is induced during fruit ripening, pollination, senescence, by wound and fungal elicitors. ACC oxidase is encoded by a multigene family but with limited divergence (Zarembinski and Theologis, 1994).

It has been suggested that two systems for the regulation of ethylene biosynthesis exist in higher plants (Lelievre et al., 1997). System I ethylene is autoinhibitory, and is functional in both climacteric and nonclimacteric fruit as well as in vegetative

Received for publication 23 Jan. 2002. Accepted for publication 18 Apr. 2002. The nucleotide sequence data reported in this paper appear in the EMBL, GenBank and DDBJ Nucleotide sequence databases under the accession numbers AF 500119 (PA-ACS1 cDNA), AF 500120 (PA-ACS2 cDNA) and AF 500121 (PA-ERS1 cDNA).

${ }^{1}$ Corresponding author; e-mail ainaba@cc.okayama-u.ac.jp. tissues, and is responsible for basal and wound-induced ethylene production. Several studies have confirmed that ACS gene expression can be negatively regulated by ethylene in vegetative tissues such as mung bean seedlings (Yoon et al., 1997), pea seedlings (Peck and Kende, 1998), preclimacteric fruit such as tomato (Barry et al., 2000; Nakatsuka et al., 1998) and in wounded winter squash tissue (Nakajima et al., 1990). The System II ethylene is autostimulatory and is a distinctive feature of ripening climacteric fruit and senescing flower petals (Lelievre et al., 1997). Recent reports have demonstrated the positive feedback regulation of ACS and ACO genes by system II ethylene in a variety of climacteric fruit such as tomato fruit (Barry et al., 2000; Nakatsuka et al., 1998, 1997), passion fruit (Mita et al., 1998), kiwifruit (Whittaker et al., 1997), and Prunus mume (Mita et al., 1999).

Genes coding for early components in the ethylene signal transduction pathway were identified by a mutational analysis approach in Arabidopsis thaliana (Schaller and Bleecker, 1995). Biochemical insights into the roles of the individual members of the ethylene receptor gene family in ethylene signal transduction have been provided by the analysis of the loss-of-function mutant phenotypes in Arabidopsis thaliana, which revealed that ethylene receptors normally act to repress responses in the absence of ethylene (Hua and Meyerowitz, 1998). The negative regulator model of ethylene receptor function in Arabidopsis leads to the prediction that up-regulation of the receptor mRNA expression would down-regulate ethylene responses (Hua and Meyerowitz, 1998). Other ethylene receptor homologues have also been isolated and expression patterns determined in several plants including, tomato (Lashbrook et al., 1998; Tieman and Klee, 1999), Rumex palustris (Vriezen et al., 1997), mung bean (Kim et al., 
1999), passion fruit (Mita et al., 1998), muskmelon (Sato-Nara et al., 1999), cucumber (Yamasaki et al., 2000), and geranium (Dervinis et al., 2000). These molecular studies have provided every reason to suppose that the receptor abundance is modulated by either ethylene, developmental or environmental factors.

The avocado (Persea americana) is a typical climacteric fruit and a prodigious ethylene producer characterized by a sharp rise and fall in the rate of ethylene production during the course of ripening. As with other climacteric fruit, a variety of genes are induced during ripening of avocados (Seymour and Tucker, 1993). To date, studies on gene expression associated with ethylene biosynthesis in avocados, have solely emphasized ACO. An ACO cDNA clone was isolated from avocados, and this ACO mRNA accumulates during fruit ripening and in response to wounding (McGarvey et al., 1992; Starrett and Laties, 1993). Strikingly, no attention has been paid to study the avocado ACS at the molecular level, despite its key role in the ethylene biosynthetic pathway. Thus in the limited number of studies which have reported on the expression of ACO in avocados, data on ACS is typically absent, and hence adequate understanding at gene expression level on the regulation of ethylene biosynthesis in avocados is still lacking.

We were interested in understanding the regulation of ethylene biosynthesis and the control of ethylene sensitivity in avocados, whereby a sharp rise and fall in ethylene production is observed during the course of ripening. With this end in view, we cloned three novel cDNAs, two of which encoded two different ACC synthases and one encoding a putative ethylene response sensor (ERS1). The expression of these three genes together with a previously cloned ACC oxidase gene (McGarvey and Christoffersen, 1990), were evaluated during natural ripening of avocados, in response to 1-MCP, propylene and wounding. 1MCP is a highly strained olefin, which binds in an apparently irreversible manner to the ethylene receptor in plant tissues and controls ethylene responses and has been shown to be a potent inhibitor, capable of delaying ethylene-induced ripening in different cultivars of avocados (Feng et al., 2000; Sisler and Serek, 1997). Propylene is an active analogue of ethylene, used in its place when it is desired to monitor endogenous ethylene production.

\section{Materials and Methods}

Plant material and treatments. Mature preclimacteric avocados were obtained from the Fruit Tree Experimental Station of the Wakayama Research Center of Agriculture, Forestry and Fisheries, in Wakayama city, Japan. The intact fruit at preclimacteric stage were either ripened naturally or placed in sealed 15 -L plastic containers, following which $5 \mu \mathrm{L} \cdot \mathrm{L}^{-1} 1-\mathrm{MCP}$ or $5000 \mu \mathrm{L} \cdot \mathrm{L}^{-1}$ propylene were injected in the container via a silicone port. Each set of treatment contained five fruit per container and the exposure period was $24 \mathrm{~h}$ at a temperature of $20^{\circ} \mathrm{C}$.

1-MCP was synthesized as described by Nakatsuka et al. (1998) and quantification was done by comparing the 1-MCP generated with the known 1-MCP concentration supplied as Ethylbloc (Rohm and Hass Inc., Gessate, Italy) using a gas chromatograph fitted with a 80-100 mesh Chromosorb PAW column and a FID detector. Fruit were exposed to 1-MCP at two different stages; immediately after harvest and at the climacteric stage. In both stages the 1-MCP treatment was repeated every 2 d until day 13 , on which the treatment was terminated.
ETHYLENE DETERMINATIONS AND SAMPLING. An individual fruit was placed in a 1.4-L airtight container for $1 \mathrm{~h}$ at $20{ }^{\circ} \mathrm{C}$. Head space gas was assayed for ethylene concentration by withdrawing a gas sample using a gas-tight hypodermic syringe and injecting it into gas chromatograph (model GC-4 CMPF; Shimadzu, Kyoto, Japan), equipped with a flame ionization detector and activated alumina column. On various days after determination of ethylene production, fruit was sampled by removing the mesocarp tissues from the equatorial region abutting the seed, frozen in liquid nitrogen and stored at $-80{ }^{\circ} \mathrm{C}$ to be used for subsequent analysis.

WOUNDING EXPERIMENTS. Intact preclimacteric avocados were either held in air or in the presence of $5 \mu \mathrm{L} \cdot \mathrm{L}^{-1} 1-\mathrm{MCP}$ for $24 \mathrm{~h}$, peeled and wounded by cutting the mesocarp tissue into small cubes $\approx 3 \mathrm{~mm}$ thick. The cubes were incubated at $25^{\circ} \mathrm{C}$ for $30 \mathrm{~h}$ under humidified conditions. Ethylene production rate was monitored and at 6,24, and $36 \mathrm{~h}$ time points, samples were withdrawn, and immediately frozen in liquid nitrogen and stored at $-80^{\circ} \mathrm{C}$.

EXTRACTION AND ASSAY OF ACC SYNTHASE, ACC OXIDASE, AND ACC CONTENT. Both ACS and ACO were extracted using the same buffer as described by Nakatsuka et al. (1997) with slight modifications. Five grams of frozen mesocarp tissue was pulverized to a fine powder under liquid nitrogen and homogenized with $20 \mathrm{~mL}$ of extraction buffer ( $\mathrm{pH} 8.5$ ) consisting of $500 \mathrm{~mm}$ potassium phosphate, $30 \mathrm{~mm}$ sodium ascorbate, $5 \mathrm{~mm}$ DTT, $5 \mathrm{~mm}$ pyridoxal phosphate, $2 \%$ polyvinylpyrrolidone (PVP), and $10 \%$ glycerol. The homogenate was filtered through four layers of cheesecloth and centrifuged at 20,000 rpm for $20 \mathrm{~min}$. The supernatant was passed through a $0.45-\mathrm{mm}$ membrane filter before loading onto prepacked sephadex G-25 columns (Pharmacia LKB, Uppsala, Sweden), previously equilibrated with $100 \mathrm{~mm}$ potassium phosphate ( $\mathrm{pH} 8.5$ ) buffer solution containing $5 \mathrm{~mm}$ DTT and $5 \mathrm{~mm}$ pyridoxal phosphate. The protein fractions were eluted with the same buffer and used in enzyme assay. All steps in enzyme extraction were done at $4{ }^{\circ} \mathrm{C}$.

ACS activity was assayed by incubating $1 \mathrm{~mL}$ of the enzyme preparation with $0.2 \mathrm{~mL}$ of $0.5 \mathrm{~mm} \mathrm{SAM}$ at $30^{\circ} \mathrm{C}$ for $30 \mathrm{~min}$, and the ACC produced was determined by the method of Lizada and Yang (1979). The enzyme activity was expressed as the amount of ACC in nanomoles produced per milligram of protein per hour.

ACO activity was assayed by incubating $1 \mathrm{~mL}$ of the enzyme preparation with $1 \mathrm{~mL}$ of a buffer solution containing $1 \mathrm{~mm} \mathrm{ACC}$, $30 \mathrm{~mm}$ sodium ascorbate, $20 \mathrm{~mm} \mathrm{NaHCO}_{3}$ and $0.1 \mathrm{~mm} \mathrm{FeSO}_{4}$ at $30{ }^{\circ} \mathrm{C}$ for $30 \mathrm{~min}$ according to the method of Moya-Leon and John (1994). The ethylene produced was then determined. The enzyme activity was expressed as the amount of ethylene in nanomoles produced per miligram of protein per hour. Protein content in the enzyme extracts was estimated by the dye-binding method of Bradford (1976) using a protein assay kit (Bio Rad, Hercules, Calif.) and bovine serum albumin as a standard. ACC in the fruit samples was extracted in $80 \%$ ethanol and the content estimated by the method of Lizada and Yang (1979) as mentioned above.

RNA EXTRACTION AND REVERSE TRANSCRIPTASE POLYMERASE CHAIN REACTION (RT-PCR). Total RNA was extracted from the frozen mesocarp tissue using the hot borate method as described by Wan and Wilkins (1994). The first strand cDNAs were synthesized using the AMV reverse transcriptase cDNA synthesis kit (Life sciences), from $10 \mu \mathrm{g}$ of total RNA, obtained from the fruit at climacteric stage. The cDNAs were then used as templates for PCR amplifications. An ACS cDNA fragment, $P A-A C S 1$, an ACC oxidase cDNA fragment, $P A-A C O$, and an ethylene receptor cDNA fragment were amplified using the set of degenerate primers for these genes previously described by Nakatsuka et al. 
(1997, 1998). When RT-PCR amplification was carried out using total RNA isolated from the wounded fruit tissue, an additional ACS fragment, $P A-A C S 2$, was obtained. Thermocycling profile was as follows: $95^{\circ} \mathrm{C}$ for $3 \mathrm{~min}$ followed by 35 cycles of $95^{\circ} \mathrm{C}$ for $1 \mathrm{~min}, 50^{\circ} \mathrm{C}$ for $1.5 \mathrm{~min}$, and then $72^{\circ} \mathrm{C}$ for $1.5 \min 72^{\circ} \mathrm{C}$ for 10 min and final hold at $4{ }^{\circ} \mathrm{C}$.

Cloning and DNA Sequencing. The cDNA fragments were cloned into pGEM-T Easy vector (Promega, Biotech, Madison, Wis.) and their nucleotide sequences determined using a DNA sequencer (model DSQ-1000; Shimadzu, Kyoto, Japan) with either $-21 \mathrm{M} 13$ or M13 sequencing primers and Thermo Sequenase Sequencing kit (Amersham Pharmacia Biotech).

cDNA LIBRARY CONSTRUCTION AND RACE-PCR. To isolate the full-length cDNA encoding PA-ACS1, we constructed a cDNA library using Lambda-ZAP II (Stratagene, La Jolla, Calif.) from poly $(\mathrm{A})^{+}$obtained from climacteric fruit. About $2 \times 10^{5}$ recombinants were screened using DIG-labeled PA-ACS1 probe generated from the amplified RT-PCR fragment. After the second screening 19 positive plaques were isolated and converted to pBluescript SK (-) phagemids. All 15 clones sequenced contained identical sequences with the exception of differences in the length of the 5' end. Our attempts to screen $P A-E R S 1$ and $P A$ $A C S 2$ cDNAs from the library were unsuccessful. Therefore, to obtain the $5^{\prime}$ and the 3 ' ends, flanking sequences of the cDNA fragments RACE-PCR was performed using the Marathon cDNA amplification kit (Clontech, Palo Alto, Calif.), according to the manufacturer's instructions, from mRNAs extracted from ripening or wounded fruit.

NORTHERN BLOT ANALYSIS. Five micrograms of total RNA was fractionated on $1 \%$ agarose gel containing $2.5 \%$ formaldehyde (v/ v). The gel was stained by ethidium bromide ( $\mathrm{EtBr})$ to check the RNA integrity and to ensure equal sample concentration, blotted overnight by capillary transfer to nylon membrane. Dig-labeled, DNA gene specific probes were generated by PCR amplification using the cloned cDNAs as template according to the manufacturer's protocol (PCR DIG probe synthesis kit, Boeringer Mannheim). A 600-bp probe corresponding to the 3'-untranslated region of the full length sequence of $P A-A C S 1$ was amplified. For the other cDNAs the coding regions were used to amplify a 708bp probe in case of $P A-A C S 2$, a 513-bp probe in case of $P A-E R S 1$ and a 900 -bp probe in case of $P A-A C O$. Hybridization was carried out overnight at $42{ }^{\circ} \mathrm{C}$ for ACC oxidase, $54{ }^{\circ} \mathrm{C}$ for ACC synthase and the ethylene receptor genes. The membranes were washed twice in $2 \times \mathrm{SSC}$ for $5 \mathrm{~min}$ at room temperature and then washed twice in $0.1 \times \mathrm{SSC}$ for $30 \mathrm{~min}$ at $65^{\circ} \mathrm{C}$ for $\mathrm{ACO}$, and $62^{\circ} \mathrm{C}$ for both ACS and ERS transcripts. The membranes were subjected to chemiluminescent reaction with CDP-Star according to the manufacturer's protocol (DIG-Detection System; Boeringer Mannheim), and then exposed to Hyperfilm ECL (Amersham Pharmarcia Biotech, U.K.).

\section{Results}

ISOLATION OF CDNAS ENCODING ACC SYNTHASE, ACC OXIDASE, AND ETHYLENE RECEPTOR. Two ACS genes, PA-ACS1 and PA$A C S 2$, one ACO gene, $P A-A C O$, and one ETR1 homolog were cloned by RT-PCR. Full-length sequence of PA-ACS1 was obtained by screening of avocado cDNA library while that of $P A$ ACS2 and PA-ETS1 was obtained by RACE-PCR technique. Since the deduced amino acid sequence of ACO cDNA fragment cloned had $99 \%$ similarity with the avocado ACO already registered in the gene bank database (McGarvey and Christoffersen,
1990), we concluded that it is the same gene and the minor differences may have been due to difference in cultivar or PCR errors. The full-length sequences of both avocado ACS genes had a $50 \%$ to $80 \%$ amino acid similarity with the ACS genes registered in the gene bank database. A phylogenetic tree was reconstructed from an alignment of the deduced amino acid sequence from the two avocado ACC synthases with other ACC synthases in the database (Fig. 1). The cladogram shown is reminiscent of the phylogram constructed for the tomato isoforms (Shiu et al., 1998). When the cladogram was correlated to the isoelectric point (pI) of the ACC synthases, both PA-ACS1 and PA-ACS2 were found to belong to the second class of ACC synthases, the class with the neutral or near neutral isoelecteric point (Fluhr and Matoo, 1996).

The avocado ethylene receptor gene obtained, had a $56 \%$ to $74 \%$ identity with the ERS 1 and ETR 1 genes registered in the gene bank database. The deduced amino acid sequence of the avocado ethylene receptor had the three putative membrane-spanning domains and the histidine kinase domain, but lacked the response regulator domain indicating that it is an ERS1 ortholog. To our knowledge, this is the first report on the cloning of ACC synthase and putative ethylene receptor genes from avocados.

ETHYLENE EVOLUTION, ACTIVITIES OF ACC SYNTHASE AND ACC OXIDASE AND ACC CONTENT DURING FRUIT RIPENING. Figure 2 shows that the control fruit at harvest produced basal levels of ethylene and had very low ACS activity $(0.01 \mathrm{nmol} \mathrm{ACC} / \mathrm{mg}$ protein per h), ACO activity $\left(0.02 \mathrm{nmol} \mathrm{C}_{2} \mathrm{H}_{4} / \mathrm{mg}\right.$ protein per h) and ACC content $\left(0.1 \mathrm{nmol} \cdot \mathrm{g}^{-1}\right)$. However ACS activity increased markedly with ripening reaching a maximum of 1.81

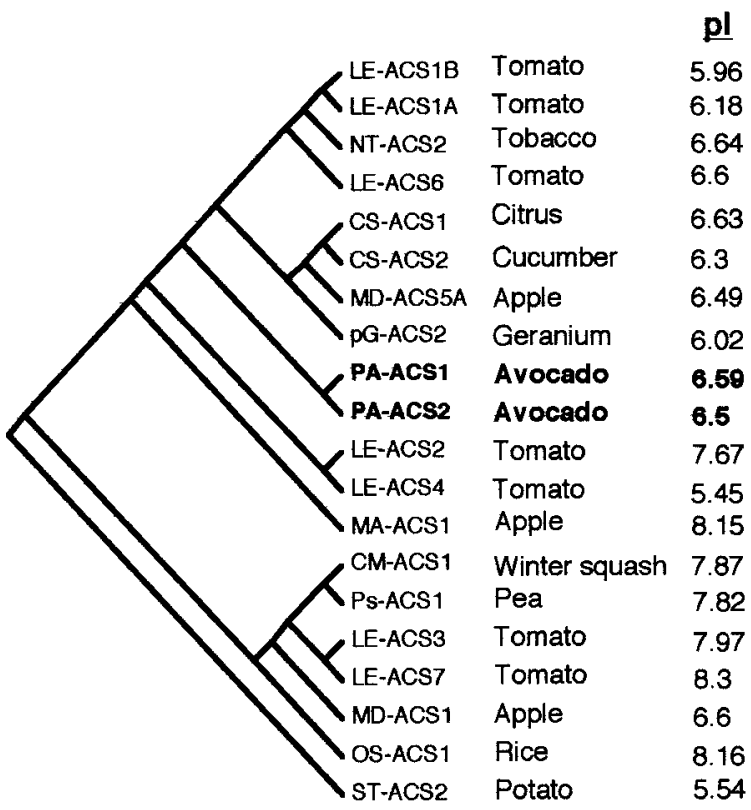

Fig. 1. Phylogenetic analysis of 20 ACC synthase clones. The cladogram was generated from the alignment of full length deduced amino acid sequences deposited in the gene bank database and was created using the clustalW and TreeView software. The GeneBank accession numbers are in parenthesis as follows: LE-ACSIA, tomato (T07596); LE-ACSIB, tomato (T07601); NTACS2, tobacco (AAC83147); LE-ACS6, tomato (BAA34923); MD-ACS5A apple (BAA92350); $p G-A C S 2$, geranium (U17231); CS-ACS1, Citrus sinensis (AJ012550); CS-ACS2, cucumber (BAA33376); LE-ACS2, tomato (S19677); LE-ACS4, tomato (S19679); MA-ACS1,(X96946); LE-ACS3, tomato (AAB48945); $L E-A C S 7$, tomato (AAC32317); $C M-A C S 1$, winter squash (Q00257); $P s-A C S 1$, pea (T06252); (MD-ACS1, apple (AAB68617); OS-ACS1, rice (Q07215); ST-ACS2, potato (S47049); PA-ACS1 and PA-ACS2, avocado (the current study). 

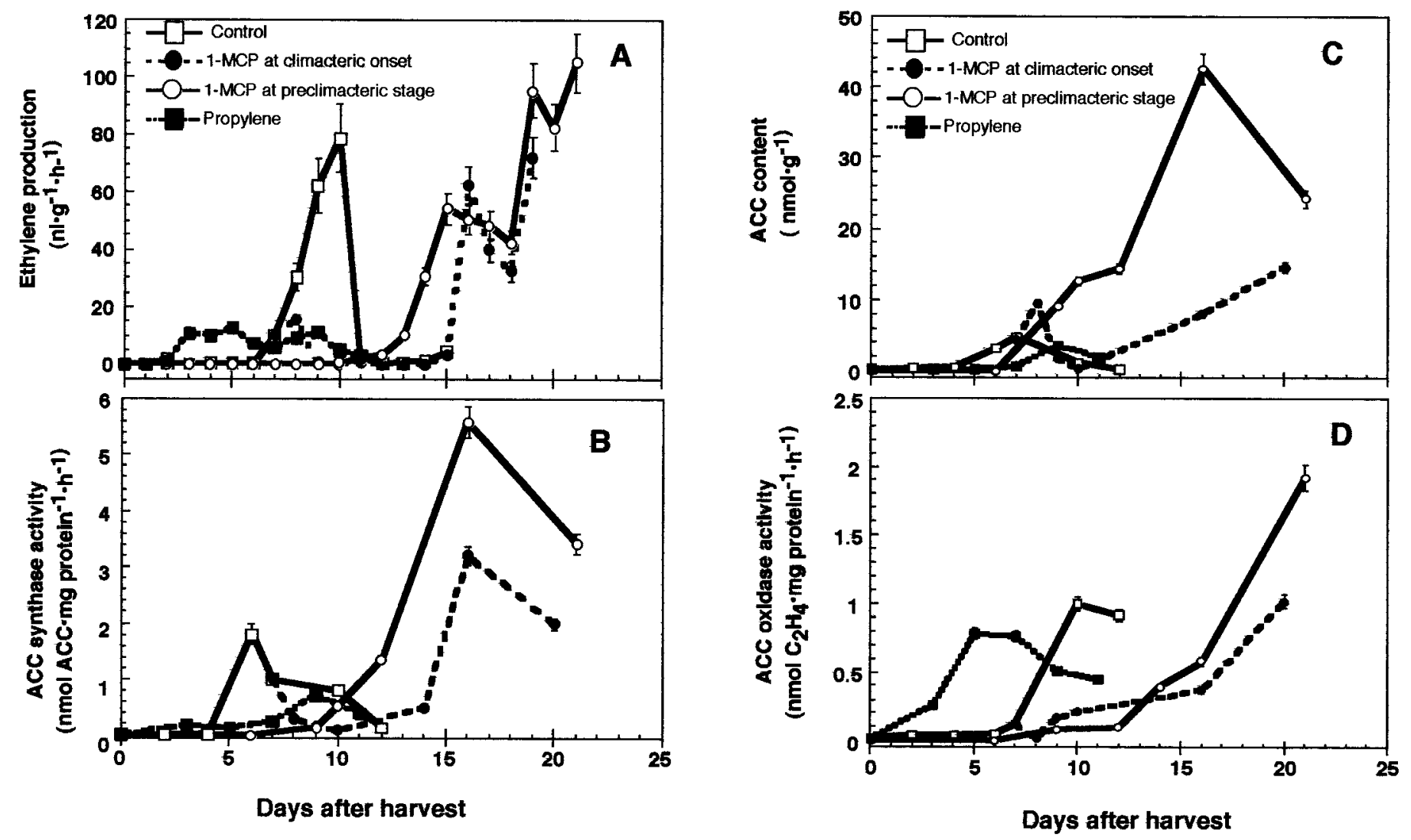

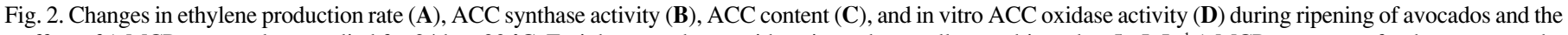
effect of 1-MCP or propylene applied for $24 \mathrm{~h}$ at $20^{\circ} \mathrm{C}$. Fruit harvested were either ripened naturally or subjected to $5 \mu \mathrm{L} \cdot \mathrm{L}^{-1} 1-\mathrm{MCP}$ treatment after harvest or at the climacteric rise or to propylene treatment at a concentration of $5000 \mu \mathrm{L} \cdot \mathrm{L}^{-1}$. Results are mean values of 10 fruit \pm SE in $\mathbf{A}$ and three replications \pm SE in $\mathbf{B}, \mathbf{C}$, and $\mathbf{D}$.

nmol ACC/mg protein per h, before the climacteric peak and thereafter declined rapidly (Fig. 2B ). ACC also accumulated rapidly during the onset of ripening, before the climacteric peak (Fig. 2C). Subsequently the ACC level dropped during and immediately after the climacteric peak. The ACO activity increased dramatically only at the beginning of the climacteric rise, with the highest activity of $1 \mathrm{nmol} \mathrm{C}_{2} \mathrm{H}_{4} / \mathrm{mg}$ protein per $\mathrm{h}$ being detected at the climacteric peak (Fig. 2D).

Propylene administered continuously evoked ethylene production by day 3 (Fig. 2A). This enhanced ethylene production was consistent with the induction of the activities of both ACS and ACO as observed on this day (Fig. 2B and D). Strikingly, throughout the ripening period, the magnitude of ethylene production was relatively low, with no distinct sharp ethylene peak observed as in the control fruit (Fig. 2A). In a similar pattern to ethylene production, the level of ACS activity and ACC content in propylene treated fruit, were low as compared to control fruit (Fig. 2B and C). ACO activity was stimulated at a much higher threshold than ACS activity, such that by day 4, it had reached almost the same level as the control fruit at the climacteric peak (Fig. 2D). 1-MCP treatment from the first day after harvest, considerably delayed the autocatalytic ethylene production (Fig. 2A). However, even under 1-MCP treatment, the fruit began to produce significant levels of ethylene as from day 11. The 1-MCP treatment was terminated on day 13 because even though the fruit appeared normal on the outside, when cut open, dark brown specks were observed on the mesocarp tissues. The dark brown specks observed on day 12 were rather minute and concentrated on the pedicel-end of the fruit, however they intensified thenceforward, coalescing into more substantial lesions, covering the entire mesocarp tissue. ACS and ACO activities were completely inhibited by 1-MCP treatment until day 9 (Fig. 2B and D). The rise in ACS and ACO activities detected on day 9, were presumably responsible for the subsequent increase in ethylene production. Termination of 1-MCP treatment, led to higher levels of ACS and ACO activities and ACC content and therefore ethylene production (Fig. 2A, B, C, and D).

Exposure of fruit to 1-MCP after the induction of autocatalytic ethylene production on day 7 resulted in a slight increase in ethylene production the following day (Fig. 2A), which subsequently decreased to a trace level, until day 14, after which it rose rapidly again. 1-MCP treatment at the climacteric rise completely inhibited ACS activity, whereas it temporarily held back the ACO activity (Fig. 2B and 2D), which later rose again, even though unaccompanied by rise in ethylene production. Similar to treatment at the preclimacteric stage, dark brown specks were also observed on the mesocarp tissues of these fruit from day 13. After 1-MCP treatment was discontinued, enhanced activities of both ACS and ACO and high levels of ethylene production were observed (Fig. 2A, B, C, and D)

EXPRESSION CHARACTERISTICS OF PA-ACS1, PA-ACS2, PA-ACO AND PA-ERS1 GENES DURING FRUIT RIPENING. Northern blot analysis showed that, in control fruit, $P A-A C S 1$ transcript was not detected on the harvest day, however a hybridization signal was detected on day 6 (Fig. 3), consistent with the peak of ACS activity. The intensity of the accumulation of this transcript slightly declined on day 7 , and thereafter did not change throughout the ripening period. The level of $P A-A C O$ transcript was evident in the control fruit on day 6 , four days before the climacteric peak. The accumulation of this transcript was gradual, 


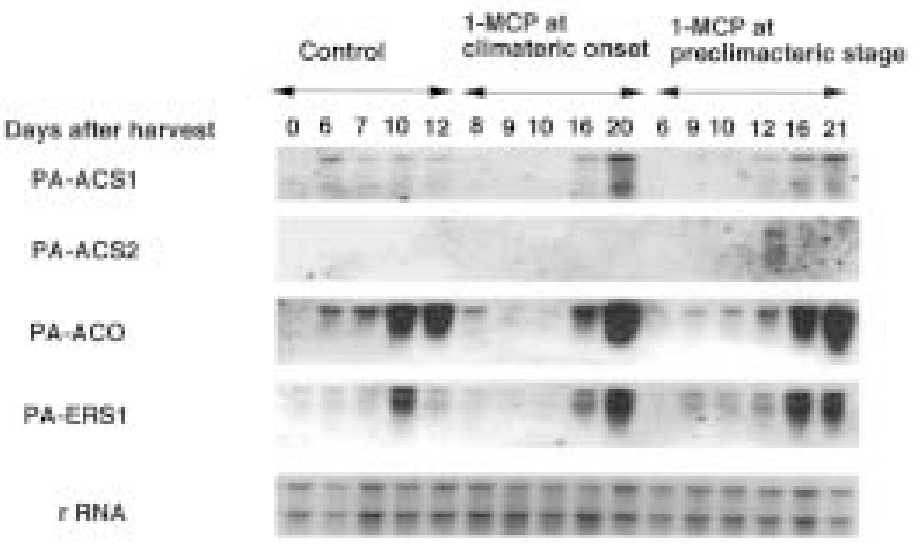

Fig. 3. Northern analysis of $P A-A C S 1, P A-A C S 2, P A-A C O$, and $P A-E R S 1$ transcripts during ripening of avocados and the effect of 1-MCP applied immediately after harvest or at the onset of the climacteric rise or $5000 \mu \mathrm{L} \cdot \mathrm{L}^{-1}$ propylene on the transcript abundance. Five micrograms of total RNA isolated from the mesocarp tissue was fractionated in $1 \%$ agarose gel containing $2.5 \%(\mathrm{~V} / \mathrm{V})$ formaldehyde and then transferred tonylon membranes. The blots were washed at low astringency $\left(20^{\circ} \mathrm{C}\right.$ below $\left.\mathrm{Tm}\right)$. The bottom panel is the ethidium bromide staining of the rRNA bands used to monitor equal loading of RNA samples.

with maximum superinduced expression at the climacteric peak and postclimacteric period. A basal level of $P A-E R S 1$ transcript was observed on harvest day and the accumulation did not change considerably until the climacteric peak of ethylene production when hyperinduction was observed. Reduction in ethylene levels at the postclimacteric stage correlated with the low level expression of the $P A-E R S 1$ transcript.

EFFECT OF 1-MCP ON GENE EXPRESSION. Continuous 1-MCP treatment from harvest day completely inhibited $P A-A C S 1$ transcript accumulation and suppressed the transcription of $P A-A C O$ and $P A-E R S 1$ to trace levels, whereas termination of $1-\mathrm{MCP}$ treatment resulted in superinduction of these transcripts (Fig. 3). $P A-A C S 2$ transcript accumulation was detected on day 12 , however termination of 1-MCP treatment led to decline of PA-ACS2 transcript to undetectable levels. Exposure of fruit to 1-MCP, after the climacteric onset on day 7, inhibited the accumulation of $P A-A C S 1$ completely, while $P A-A C O$ and $P A-E R S 1$ transcripts were suppressed to trace levels (Fig. 4). Discontinuation of 1MCP treatment on day 14 led to superinduction of $P A-A C S 1, P A-$ $A C O$, and $P A-E R S 1$ transcripts.

EFFECT OF PROPYLENE ON GENE EXPRESSION. Propylene treatment induced the transcription of $P A-A C S 1$ and $P A-A C O$ by day 3 correlating with the ethylene production (Fig. 3). The induction of $P A-A C O$ by exogenous propylene was much more significant as compared to $P A-A C S 1$. The $P A-E R S 1 \mathrm{mRNA}$ expression was significantly enhanced by propylene even though at a lesser degree compared to the hyperinduction at the climacteric peak in control fruit.

WOUND-INDUCED ETHYLENE BIOSYNTHESIS AND GENE EXPRESSION. Ethylene production induced by wounding was detectable at $3 \mathrm{~h}$ and peaked at $24 \mathrm{~h}$ (Fig. 4A). Detectable levels of PA-ACS1 were observed in control sample between $6 \mathrm{~h}$ and $24 \mathrm{~h}$, whereas no accumulation of the transcript was detected until $36 \mathrm{~h}$ in the 1MCP pretreated tissue (Fig. 4B). PA-ACS2 mRNA accumulation was transiently induced in both control and in 1-MCP pretreated tissue, but higher level was observed in 1-MCP pretreated tissues. $P A-A C O$ transcript accumulation was induced in both control and $1-\mathrm{MCP}$ pretreated tissues. $P A-E R S 1$ expression was enhanced in the control tissues between 6 and $24 \mathrm{~h}$, but declined after $36 \mathrm{~h}$,

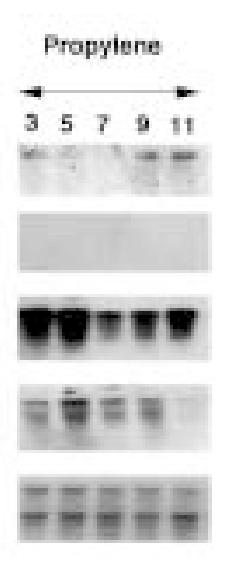

whereas a low level expression was detected after $6 \mathrm{~h}$ under 1-MCP, which increased after $24 \mathrm{~h}$ and later declined after $36 \mathrm{~h}$.

\section{Discussion}

Cloning and sequence analysis of CLONED cDNAs. Optimal alignments of the $P A-A C S 1$ and $P A-A C S 2$ genes show $67 \%$ identity between the nucleotide sequences and $70.2 \%$ similarity between the amino acid sequences. The low homology observed between $P A-A C S 1$ and $P A-A C S 2$ is a characteristic feature of ACC synthase gene family (Rottman et al., 1991). It has been suggested

A

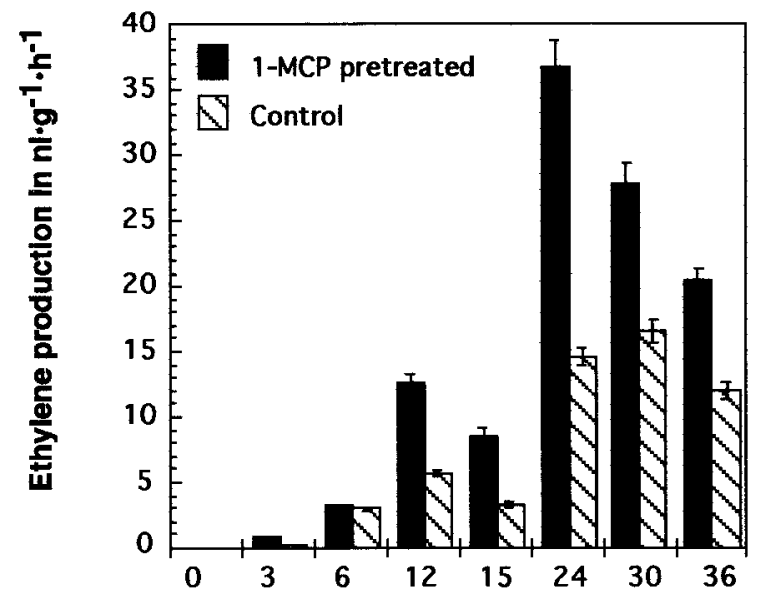

Hours after wounding

B Control 1-MCP pre-treated

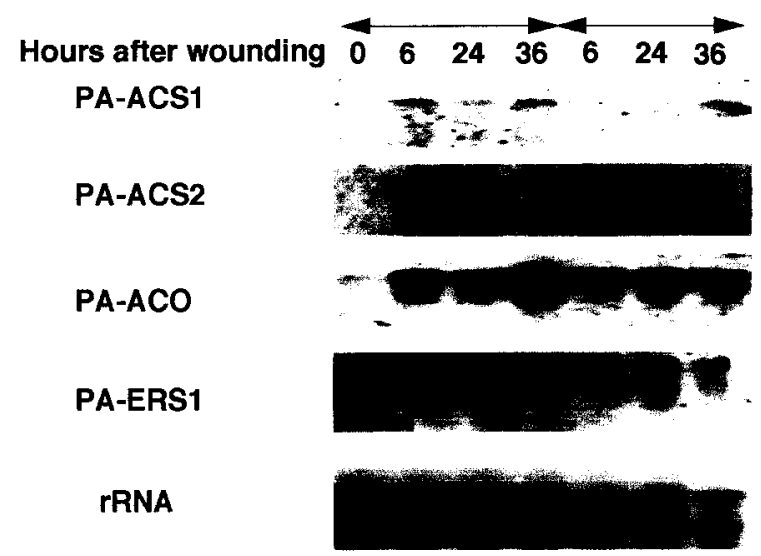

Fig. 4. Time course analysis of wound induced ethylene biosynthesis. (A) Comparison of the ethylene production rates of wounded tissue after 1-MCP pretreatment or without 1-MCP pretreatment. Preclimacteric avocados were either held in air (control) or in the presence of 1-MCP at $20^{\circ} \mathrm{C}$ for $24 \mathrm{~h}$ and subjected to wounding by slicing into small pieces. Ethylene production was determined at the times indicated. Data are mean values of three replications \pm SE. (B) The effect of 1-MCP pretreatment on PA-ACS1, PA-ACS2, PA-ACO and $P A$-ERS1 transcripts abundance after wounding. After determination of ethylene production at $0,6,24$, and $36 \mathrm{~h}$ time points in A, samples were withdrawn and immediately frozen in liquid $\mathrm{N}_{2}$ for subsequent Northern analysis. Details of the Northern blot are as described in the legend of Fig. 3. 
that the reason for this lower than usual conservation, maybe due to the evolution of a set of ACC synthase gene products catalyzing specific reactions, thus enabling the conversion of SAM to ACC under different cellular conditions (Rottman et al., 1991). When the constructed cladogram was correlated with the isoelectric points (pI), $P A-A C S 1$ and $P A-A C S 2$ were found to fall in the class 2 ACC synthase genes (Fig 1). The acidic ACC synthases are the class 1 types with a pI of below 5.74, while the neutral and the near neutral ACC synthases are the class 2 types with a pI of between 6.21 and 7.86 and the alkaline ACC synthases are class 3 types with a pI >8.00 (Fluhr and Mattoo, 1996; Shiu et al., 1998). In most other plant species, it has been suggested that wounding and auxin inducibility evolved before the polymorphism of the ACS genes (Wong et al., 1999). However in the case of avocados, both ACS genes are orthologous, with $P A-A C S 1$ being the progenitor of $P A-A C S 2$. The active site of ACC synthase is well conserved in the proteins encoded by both genes and $P A-A C S 2$ protein contains all the 11 amino acid residues conserved among the subgroup I aminotransferases and ACC synthases (Rottman et al., 1991) whereas $P A-A C S 1$ contains 10 of them. In $P A-A C S 1$, Phe residue is at position 241 instead of the normally conserved Tyr. This Tyr is not absolutely conserved in all ACC synthases, since mutation to Phe results in mutant enzymes that are fairly active with $36 \%$ of wild type activity (Tarun et al., 1998). It has been suggested that this Tyr plays a role in orienting the PLP cofactor in the active site and that the additional hydrogen bond from Tyr to PLP is not very important based on the kinetic properties of the Y233F mutant (Tarun et al., 1998).

REGULATION OF ETHYLENE BIOSYNTHESIS DURING FRUIT RIPENING. Fruit at harvest produced very low amounts of ethylene (Fig 2A). Though the ACS activity reached a maximum on day 6, no significant increase in ethylene production was observed due to low levels of ACO activity. $P A-A C O$ transcript accumulation and ACO activity started to increase steadily on day 7 reaching a peak on day 10 , concomitant with the ethylene production. Even though ethylene production decreases rapidly, the $P A-A C O$ transcript accumulation and ACO activity at the postclimacteric stage were still quite high. Thus the current study verifies previous observations, which have indicated that ACS activity and ACC level in ripening avocados reaches a maximum before that of ACO activity (Sitrit et al., 1986). Parenthetically, although coordinate induction of both ACS and ACO genes has to occur to trigger the autocatalytic ethylene production, ACO seems to be the first key factor in this phenomenon (Fluhr and Mattoo, 1996). As a result, enhanced expression of ACO mRNA and increased ACO activity occurs earlier than that of ACS. This is best exemplified by results obtained with several climacteric fruit during ripening such as tomato, apple, passion fruit, and Kiwifruit (Mita et al., 1998; Nakatsuka et al, 1998; Whittaker et al., 1997). Notwithstanding, during ripening of Mume fruit, increase in the abundance of ACS mRNA and the activity of ACS activity occurs earlier than that of ACO (Mita et al., 1999). Thus it appears that the order of precedence in enhanced expression between ACS and ACO genes and hence the activities of the two enzymes during ripening of climacteric fruit vary from one fruit to another. Our data indicate that the induction of $P A-A C S 1$ seemingly precedes that of $P A-A C O$ during ripening of avocados and suggest that, the stimulation of $P A-A C O$ is a central important factor in the overall induction of high levels of ethylene production during ripening of avocados.

Propylene sharply augmented both the expressions of $P A$ $A C O$ mRNA and ACO activity. However, an intriguing phenom- enon was the markedly low level of ACC synthase activity, ACC content and ethylene production observed in propylene treated fruit. Zauberman et al. (1988) reported that $100 \mu \mathrm{L} \cdot \mathrm{L}^{-1}$ of exogenous ethylene treatment applied for $24 \mathrm{~h}$ reduced markedly the amount of ethylene produced by avocados. Reduction of ethylene production by ethylene at the climacteric stage has also been reported in bananas (Vendrell and McGlasson, 1971). Since our data show that it was the ACC synthase activity that was affected, we hypothesize that, maybe, the high concentration of exogenous propylene or ethylene exerts a reductive effect (not inhibitory effect) on ACS activity, leading to a low ACC pool. Therefore, even though the ACO activity is highly stimulated by propylene it has access to only low levels of ACC and this leads to low ethylene production.

Application of 1-MCP to banana fruit after the onset of autocatalytic ethylene production had no effect on the progress of the climacteric rise (Golding et al., 1998). However, in tomato, 1MCP treatment at the turning and pink stages, inhibited the increase in ethylene production by $\approx 66 \%$ and $75 \%$, respectively, $2 \mathrm{~d}$ after 1-MCP pretreatment. At both stages in tomato, the abundance of $L E-A C S 2, L E-A C S 4$ and $N R$ mRNA transcripts almost completely disappeared whereas $L E-A C O$ was considerably prevented (Nakatsuka et al., 1998). To test the effect of 1MCP on the progress of autocatalytic ethylene production, we treated avocados at the onset of climacteric rise. After $24 \mathrm{~h}$ treatment, ethylene production was considerably reduced and the transcription of $P A-A C S 1$ was eliminated whereas the $P A-A C O$ mRNA was suppressed to trace levels. Discontinuation of 1-MCP led to stimulated accumulation of the transcripts. This suggests that ethylene production after the onset of the climacteric in avocados is still susceptible to inhibition by 1-MCP. The ACS activity also dropped to zero levels, while ACO activity was temporarily held back but later increased, suggesting that it is the buildup of the ACO activity that is impaired and not activity per se.

The ETHYLEne Signal TRANSDUCTION PATHWay. It is widely appreciated that both ethylene biosynthesis and ethylene perception contributes to the regulation of ethylene responses in plant tissues. In the present study, we isolated one ethylene response sensor gene, $P A-E R S 1$, and examined its expression during natural ripening and in response to $1-\mathrm{MCP}$ or propylene treatment. Our data demonstrate that basal levels of $P A-E R S 1$ transcript accumulation was observed from the day of harvest, and did not change significantly until the climacteric peak when it was hyperinduced (Fig 3). This is quite contrary to the ethylene dependent tomato $N R$ gene. The tomato NR transcripts increased from basal levels to maximal levels coordinately with endogenous ethylene (Wilkinson et al., 1995). Furthermore ethylene inducibility of the $N R$ mRNA was observed when mature green wild-type fruit was treated with ethylene. The low levels of $N R$ mRNA observed in the absence of ethylene rapidly accumulated after $8 \mathrm{~h}$ upon ethylene exposure to amounts comparable to those observed at later stages of ripening (Wilkinson et al., 1995). Even though there was a significant increase in $P A-E R S 1$ transcript accumulation upon propylene treatment, the induction was much less as compared to the hyperinduction at the climacteric peak. It is possible that $P A-E R S 1$ was not significantly induced in propylene treated fruit due to the low level ethylene produced by these fruit. 1-MCP however, suppressed the accumulation of PA-ERS1 to basal levels and discontinuation of 1-MCP treatment led to superinduction of this transcript. The hyperinduction of $P A-E R S 1$ mRNA was observed at two instances; at the climacteric peak and 
after the discontinuation of 1-MCP pretreatment when the fruit were producing enormous levels of ethylene, suggesting that $P A$ ERS1 mRNA accumulation occurs only at a specific ethylene threshold. We suggest that for avocados to maintain homeostasis due to the large amounts of ethylene suddenly produced, high levels of ERS1 receptors are generated as a counter measure to regulate the tissue responsiveness to ethylene. This may explain the sharp rise and fall in ethylene production in avocados.

WOUND-INDUCED ETHYLENE BIOSYNTHESIS. Wound-induced ethylene accelerated events that normally take place over an extended period in intact avocado by stimulating the onset of climacteric ethylene (Starrett and Laties, 1993). In this study, wound ethylene production was enhanced by 1-MCP pretreatment, indicating that wound ethylene biosynthesis in avocados is under a negative feedback regulation. Transient accumulation of $P A-A C S 2$ transcript was observed after wounding, both in the control and in 1-MCP pretreated tissue, though the accumulation was highly induced by 1-MCP pretreatment. This indicates that $P A-A C S 2$ is the wound-inducible ACS gene in avocados and is negatively regulated by ethylene. 1-MCP seemingly did not have any effect on the accumulation of $P A-A C O$ transcript abundance. Whereas there is no doubt that the $P A-A C O$ accumulation is induced by ethylene in intact fruit, this gene represents a gene that can be induced by either ethylene or wounding per se (Starrett and Laties, 1993). With this context, it is worth mentioning that the melon $C M-A C O 1$ expression is also induced by ethylene treatment or upon wounding, and functional studies of the $C M-A C O I$ promoter suggested that wound and ethylene induction of this gene occurs via two direct and independent transduction pathways (Bouquin et al., 1997). In spite of the fact that two distinct ACC oxidase proteins have been demonstrated in avocados (McGarvey and Christoffersen, 1992), there has been no report of more than one ACC oxidase gene in avocados. Thus it appears that the wound and propylene induction of $P A-A C O 1$ may also be under two distinct and independent transduction pathways. The $P A-E R S 1$ transcript accumulation in the control-wound tissue was induced after $6 \mathrm{~h}$, thereafter its abundance did not significantly change. However 1-MCP pretreatment, led to low accumulation of this gene at $6 \mathrm{~h}$, which peaked at $24 \mathrm{~h}$ and later declined. Elevated expression of PA-ERSI observed after $24 \mathrm{~h}$ in the 1-MCP pretreated tissue indicates that sufficient numbers of new ethylene binding sites were being synthesized or binding sites were being dissociated from 1-MCP with subsequent attenuation of the ethylene response (Sisler and Serek, 1997). The transient nature of $P A-A C S 2$ gene expression suggests that the wound ethylene level is sufficient enough to sensitize the tissues for ripening initiation, and after about $15 \mathrm{~h}$ the wound ethylene gradually gives in to climacteric ethylene production.

\section{Conclusions}

In summary, we described the regulation of two ACC synthase genes, one ACC oxidase gene, and one ethylene receptor gene during ripening of avocados. These results indicate positive feedback regulation of $P A-A C S 1$ gene and negative feedback regulation of $P A-A C S 2$ gene by ethylene, while $P A-A C O$ exhibits positive feedback regulation by ethylene and is also induced upon tissue wounding. The expression kinetics and the patterns of the enzyme activities indicate that $P A-A C S 1$ mRNA and ACC synthase activity reach a maximum prior to the climacteric peak of ethylene production, whereas superinduced expression of $P A$ $A C O$ and increase in ACC oxidase activity occur at the climac- teric peak of ethylene production. The hyperinduction of $P A$ ERSI mRNA at relatively high concentrations of ethylene may be a mechanism of avocados to regulate the ethylene responsiveness of the tissues by dissipation of the ethylene gas.

\section{Literature Cited}

Barry, C.S., M.I. Llop-Tous, and D. Grierson. 2000. The regulation of 1aminocyclopropane-1-carboxylic acid synthase gene expression during the transition from system-1 to system-2 ethylene synthesis in tomato. Plant Physiol. 123:979-986.

Bouquin, T., E. Lasserre, J. Pradier, J.C. Pech, and C. Balague. 1997. Wound and ethylene induction of the ACC oxidase melon gene $C M$ $A C O 1$ occurs via two direct and independent transduction pathways. Plant Mol. Biol. 35:1029-1035.

Bradford, M.M. 1976. A rapid and sensitive method for quantification of microgram quantities of protein utilizing the principle of protein-dye binding. Anal. Biochem. 72:248-254.

Dervinis, C., D.G. Clark, J.E. Barrett, and T.A. Nell. 2000. Effect of pollination and exogenous ethylene on accumulation of ETR1 homologue transcripts during flower petal abscission in geranium (Pelargonium $\times$ hortorum L.H. Bailey). Plant Mol. Biol. 42:847-856.

Feng, X., A. Apelbaum, E. Sisler, and R. Goren. 2000. Control of ethylene responses in avocado fruit with 1-methylcyclopropane. Postharvest Biol. Technol. 20:143-150.

Fluhr, R. and A.K. Mattoo. 1996. Ethylene-Biosynthesis and perception. Crit. Rev. Plant Sci. 15:479-523.

Golding, J.B., D. Shearer, S.G. Wyllie, and W.B. McGlasson. 1998. Application of 1-MCP and propylene to identify ethylene-dependent ripening processes in mature banana fruit. Postharvest Biol. Technol. 14:87-98.

Hua, J. and E.M. Meyerowitz. 1998. Ethylene responses are negatively regulated by a receptor gene family in Arabidospsis thaliana. Cell 94:261-271.

Kim, J.H., J.H. Lee, S. Joo, and W.T. Kim. 1999. Ethylene regulation of an ERS1 homolog in mung bean seedlings. Physiol. Plant. 106:90-97.

Lashbrook, C.C., D.M. Tieman, and H.J. Klee. 1998. Differential regulation of the tomato ETR gene family throughout plant development. Plant J. 15:243-252.

Lelievre, J.M., A. Latche, B. Jones, M. Bouzayen, and J.C. Pech. 1997. Ethylene and fruit ripening. Physiol. Plant. 101:727-739.

Lizada, M.C. and S.F. Yang. 1979. A simple and sensitive assay for 1aminocyclopropane-1-carboxylic acid. Anal. Biochem. 100:140-145.

McGarvey, D.J., R. Sirevag, and R.E. Christoffersen. 1992. Ripening related gene from avocado fruit. Ethylene inducible expression of the mRNA and polypeptide. Plant Physiol. 98: 554-559.

McGarvey, D.J., H. Yu, and R.E. Christoffersen. 1990. Nucleotide sequence of a ripening-related complementary DNA from avocado fruit. Plant Mol. Biol. 15:165-168.

Mita, S., S. Kawamura, K. Yamawaki, K. Nakamura, and H. Hyodo. 1998. Differential expression of genes involved in the biosynthesis and perception of ethylene during ripening of passion fruit (Passiflora edulis Sims). Plant Cell Physiol. 39:1209-1217.

Mita, S., C. Kirita, M. Kato, and H. Hyodo. 1999. Expression of ACC synthase is enhanced earlier than that of ACC oxidase during fruit ripening of mume (Prunus mume). Physiol. Plant. 107:319-328.

Moya-Leon, M.A. and P. John. 1994. Activity of 1-aminocyclopropane1-carboxylate (ACC) oxidase (ethylene-forming enzyme) in the pulp and peel of ripening bananas. J. Hort. Sci. 69:243-250.

Nakajima, N., H. Mori, K. Yamazaki, and H. Imaseki. 1990. Molecular cloning and sequence of a complementary DNA encoding 1aminocyclopropane-1-carboxylate synthase induced by tissue wounding. Plant Cell Physiol. 31:1021-1029.

Nakatsuka, A., S. Murachi, H. Okunishi, S. Shiomi, R. Nakano, Y. Kubo, and A. Inaba. 1998. Differential expression and internal feedback regulation of 1-aminocyclopropane-1-carboxylate synthase, 1aminocyclopropane-1-carboxylate oxidase, and ethylene receptor genes in tomato fruit during development and ripening. Plant Physiol. 
118:1295-1305.

Nakatsuka, A., S. Shiomi, Y. Kubo, and A. Inaba. 1997. Expression and internal feedback regulation of ACC synthase and ACC oxidase genes in ripening tomato fruit. Plant Cell Physiol. 38:1103-1110.

Peck, S.C. and H. Kende. 1998. Differential regulation of genes encoding 1-aminocyclopropane-1-carboxylate (ACC) synthase in etiolated pea seedlings: Effects of indole-3-acetic acid, wounding, and ethylene. Plant Mol. Biol. 6:977-982.

Rottmann, W.H., G.F. Peter, P.W. Oeller, J.A. Keller, N.F. Shen, B.P. Nagy, L.P. Taylor, A.D. Campbell, and A. Theologis. 1991. 1aminocyclopropane-1-carboxylate synthase in tomato is encoded by a multigene family whose transcription is induced during fruit and floral senescence. J. Mol. Biol. 222:937-961.

Sato-Nara, K., K.I. Yuhashi, K. Higashi, K. Hosoya, M. Kubota, and H. Ezura. 1999. Stage- and tissue-specific expression of ethylene receptor homolog genes during fruit development in muskmelon. Plant Physiol. 120:321-330.

Schaller, G.E. and A.B. Bleecker. 1995. Ethylene binding sites generated in yeast expressing the Arabidopsis ETR1 gene. Science 270:18091811.

Seymour, G.B. and G.A. Tucker. 1993. Avocado, p. 53-81. In: G.B. Seymour, J. Taylor, and G.A. Tucker (eds.). Biochemistry of fruit ripening. Chapman and Hall, London.

Shiu, O.Y., J.H. Oetiker, W.K. Yip, and S.F. Yang. 1998. The promoter of LE-ACS7, an early flooding-induced 1-aminocyclopropane-1-carboxylate synthase gene of the tomato, is tagged by a Sol3 transposon. Proc. Natl. Acad. Sci. USA 95:10334-10339.

Sisler, E.C. and M. Serek. 1997. Inhibitors of ethylene responses in plants at the receptor level: Recent developments. Physiol. Plant. 100:577-582.

Sitrit, Y., J. Riov, and A. Blumefeld. 1986. Regulation of ethylene biosynthesis in avocado fruit ripening. Plant Physiol. 81:130-135.

Starrett, D.A. and G.G. Laties. 1993. Ethylene and wound-induced gene expression in the preclimacteric phase of ripening avocado fruit and mesocarp discs. Plant Physiol. 103:227-234.

Stepanova, N.A and J.R. Ecker. 2000. Ethylene signaling: From mutants to molecules. Current Opin. Plant Biol. 3:353-360.

Tarun, A.S., J.S. Lee, and A. Theologis. 1998. Random mutagenesis of 1-aminocyclopropane-1-carboxylate synthase: A key enzyme in ethylene biosynthesis. Proc. Natl. Acad. Sci. USA 95:9796-9780.

Tieman, D.M. and H.J. Klee. 1999. Differential expression of two novel members of the tomato ethylene-receptor family. Plant Physiol. 120:165-172.

Vendrell, M. and W.B. McGlasson. 1971. Inhibition of ethylene production in banana fruit tissue by ethylene treatment. Austral. J. Biol. Sci. 24:885-895.

Vriezen, W.H., C.P. van Rijn, L.A. Voesenek, and C. Mariani. 1997. A homolog of the Arabidopsis thaliana ERS gene is actively regulated in Rumex palustris upon flooding. Plant J. 11:1265-1271.

Wan, C.Y. and T.A. Wilkins. 1994. A modified hot borate method significantly enhances the yield of high quality RNA from cotton (Gossypium hisrstum L.). Anal. Biochem. 223:7-12.

Whittaker, D.J., G.S. Smith, and RC. Gardner. 1997. Expression of ethylene biosynthetic genes in Actinidia chinensis fruit. Plant Mol. Biol. 34(1):45-55.

Wilkinson, J.Q., M.B. Lanahan, H.C. Yen, J.J. Giovannoni, and H.J. Klee. 1995. An ethylene-inducible component of signal transduction encoded by never-ripe. Science 270:1807-1809.

Wong, W.S., W. Ning, P.L. Xu, S.D. Kung, S.F.Yang, and N. Li. 1999. Identification of two chilling-regulated 1-aminocyclopropane-1-carboxylate synthase genes from citrus (Citrus sinensis Osbeck) fruit. Plant Mol. Biol. 41:587-00.

Yamasaki, S., N. Fujii, and H. Takahashi. 2000. The ethylene-regulated expression of $C S$-ETR 2 and $C S$-ERS genes in cucumber plants and their possible involvement with sex expression in flowers. Plant Cell Physiol. 41:608-616.

Yang, S.F. and N.E. Hoffman. 1984. Ethylene biosynthesis and its regulation in higher plants. Annu. Rev. Plant Physiol. 35:155-189.

Yoon, I.S., H. Mori, J.H. Kim, B.G. Kang, and H. Imaseki. 1997. VRACS6 is an auxin-inducible 1-aminocyclopropane-1-carboxylate synthase in mung bean (Vigna radiata). Plant Cell Physiol. 38:217-224.

Zarembiski, T.I. and A. Theologis. 1994. Ethylene biosynthesis and action: A case of conservation. Plant Mol. Biol. 26:1579-1597.

Zauberman, G., Y. Fuchs, U. Yanko, and M. Akerman. 1988. Response of mature avocado fruit to postharvest ethylene treatment immediately after harvest. HortScience 23:588-589. 